\title{
The Effect of Wet Cupping Therapy on Blood Pressure and Total Cholesterol on Healthy Young Male Adults
}

\author{
Syahruramdhani Syahruramdhani*, Falasifah Ani Yuniarti, Tri Ega Septiana, Evi Mustikasari \\ School of Nursing, Faculty of Medicine and Health Sciences, Universitas Muhammadiyah Yogyakarta, Indonesia
}

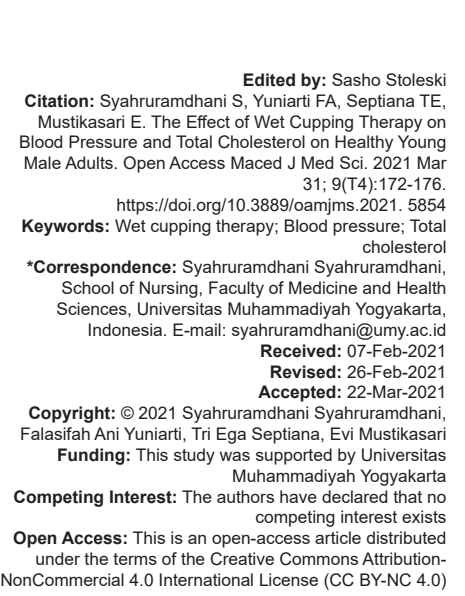

\section{Abstract}

BACKGROUND: Hypertension and hypercholesterolemia are most predisposition factors and show a significant impact in causing cardiovascular disease. Therefore, it is recommended to conduct dietary modifications, physical activity, and alternative therapies. One such option for alternative therapies is wet cupping therapy.

AIM: This study aims to investigate the effect of wet cupping on blood pressure (BP) and total cholesterol (TC) on healthy young male adults.

METHODS: This study design was quasi-experimental with a control and intervention group. It was conducted between January and February 2020 at Mini Hospital, School of Nursing, Universitas Muhammadiyah Yogyakarta. There were 44 healthy young male adults divided into control $(n=22)$ and intervention $(n=22)$ groups. This study's outcomes were BP (systolic BP [SBP] and diastolic BP [DBP]) and TC.

RESULTS: In the intervention group's post-test, the mean SBP and DBP were substantially different from the pretest $(p=0.01$ and 0.03 ). Although there was no statistically significant difference in TC outcome, overall cholestero decreased following an intervention. There was no statistically significant difference in the outcome between the control and intervention groups, except for TC, which was significantly lower in the post-test than in the pre-test.

CONCLUSION: This study's results indicated that wet cupping could be useful in decreasing BP and total cholesterol.

\section{Introduction}

Cardiovascular disease is defined as a disease related to the heart and blood vessels [1]. Hypertension and hypercholesterolemia are most predisposition factors and show a significant impact in causing cardiovascular disease [2], [3]. The prevalence of hypertension is predicted to hit over a billion people by 2025 [4]. Hypercholesterolemia refers to excessively high plasma cholesterol levels, which predispose cardiovascular diseases to many diseases [5]. Cholesterol levels in the blood should be controlled to prevent the negative consequences of hypercholesterolemia.

Despite its prevalence, it has yet to discover the right cure for the disease. All anti-hypertension and anti-hypercholesterolemia medicines are currently available to control blood pressure (BP) and cholesterol but have more side effects and high costs [6]. For hypertension and hypercholesterolemic condition, dietary modifications, physical activity, and alternative therapies are recommended to be conducted [7]. One such option for alternative therapies is cupping therapy.
Cupping therapy is a traditional treatment used to create suction on the skin over a painful area or acupuncture point using a bamboo or glass cup [8]. Cupping is an Islamic healing technique practiced in many countries all over the world [9]. In the general categories, cupping therapy is divided into dry and wet cupping. Wet cupping affects the enhancement of blood supply and activates the autonomous nerves [10].

Even though cupping is very well known globally for centuries, its effectiveness has not been scientifically studied for most common diseases. The latest studies have examined the effectiveness of wet cupping in treating hypertension. Three accredited Hijama centers (study group) obtained the data from 30 patient files, while data from the remaining 30 patient files were collected from a hospital (control group). There were 30 patient files from Hijama centers (study group), and 30 patients files from a hospital (control group) were obtained. The data were collected for both systolic BP (SBP) and diastolic BP (DBP) over 3 months. The results showed a substantial decrease in SBP, but this was not significant for DBP [11].

A critical study has investigated the efficacy of cupping therapy in hypercholesterolemia. Forty women 
in post-menopause with hypercholesterolemia were randomized into two groups. The first group received cupping therapy for 3 months, and the second group was without any intervention. All blood samples were taken after $12 \mathrm{~h}$ of fasting. Post-treatment associated with both groups demonstrated a statistically significant reduction in total cholesterol (TC) serum levels [12].

$A$ recent study assessed the influence of wet cupping on BP and cholesterol. In this study, 20 healthy females (aged 25-38) were selected as subjects for wet cupping. Their blood samples were obtained, and a routine biochemical examination was performed twice, at baseline time once before wet cupping, and then after 10 days of wet cupping. The blood examination results were compared, and it was found that after wet cupping, BP and TC were substantially reduced [13].

However, most studies conducted wet cupping on adult women, hypertension, and hypercholesterolemia patients, and blood samples were collected after $12 \mathrm{~h}$ and 10 days. Consequently, further research is needed to prove wet cupping efficacy toward BP and TC on healthy young men adults.

\section{Methods}

\section{Research design}

This study design was quasi-experimental with a control and intervention group. It was conducted between January and February 2020 at Mini Hospital, School of Nursing, Universitas Muhammadiyah Yogyakarta. The Ethics Commission approved the study of the Faculty of Medicine and Health Sciences Universitas Muhammadiyah Yogyakarta with an ethic number of 002/EP-FKIK-UMY/I/2020.

\section{Participants}

Participants were required to be healthy young adults aged 18-23 years old. Participants were Nursing Students of Universitas Muhammadiyah Yogyakarta and recruited through social media and by word of mouth. Participants were excluded if they were those with high fasting blood glucose, medication, or abnormal body temperature [13]. The sampling of this study was purposive, and the sample size used the Slovin formula with e (error tolerance) $=10 \%(0.1)$ from 80 total population. There were 44 respondents divided into control $(n=22)$ and intervention $(n=22)$ groups.

\section{Intervention}

In the control group, the participants did not get any therapy. In the intervention group, wet cupping was implemented only in a single session. The participants were advised not to eat at least $2 \mathrm{~h}$ before wet cupping. The puncture was performed at five sites (Figure 1). The first site was called Al-Khail (in Arabic), located across from T1-T3. The second location was two sites in mid-clavicular. The third location was two sites in 3 $\mathrm{cm}$ from the vertebra [14].

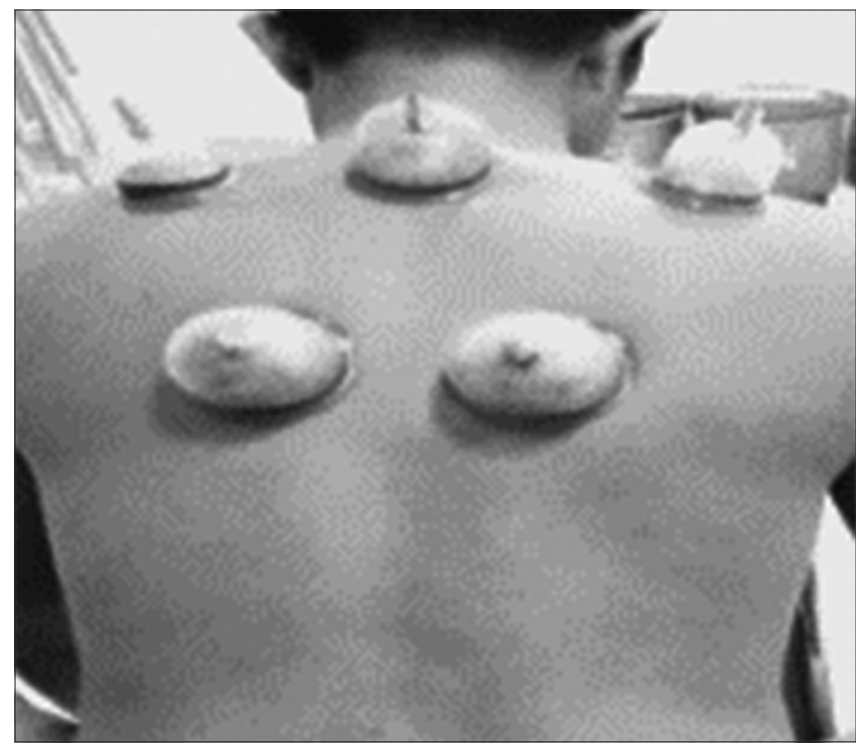

Figure 1: Five site of wet cupping

The wet cupping procedure began with cleaning the sites with an alcohol pad, putting the cup at the location, and starting suction. Furthermore, the cup was softly taken off, and a puncture was made in the area. The cup was put over the same sites after the puncturing was made, and the suctioning was repeated [9]. The cupping process was repeated 1-2 times without puncturing, and then, the sites were cleaned and dressed.

\section{Outcome measures}

This study's outcomes were BP (SBP and DBP) and TC. Standard value of SBP, DBP, and TC for male adult is $<120 \mathrm{mmHg},<80 \mathrm{mmHg}$, and $\geq 200 \mathrm{mg} / \mathrm{dL}$, respectively. Both $\mathrm{BP}$ measurements were carried out in a seated position with the patient using an automated digital sphygmomanometer (Omron, Japan). The participants' blood sample was obtained, and TC was measured by a cholesterol meter device (Easy Touch 3 in 1). Both BP and TC examinations were performed twice before and after 15 min of intervention.

\section{Statistical analysis}

Statistical analysis was performed using IBM SPSS software. They contrasted the baseline data between the two reference classes. As the data are non-normal distribution, a comparison between SBP, DBP, and TC pre-test and post-test of wet cupping was conducted using the Wilcoxon signed-rank test. Whereas comparison between the control and 
intervention groups was performed by the MannWhitney U-test. $p<0.05$ was considered statistically significant.

\section{Results}

Table 1 shows that the mean age of participants in the control and intervention groups is 20 (20.36) years old. The youngest is 18 , and the oldest is 23 years old.

Table 1: Characteristic of participants

\begin{tabular}{lll}
\hline Characteristic & Mean \pm SD & \\
\cline { 2 - 3 } & Control $(\mathrm{n}=22)$ & Intervention $(\mathrm{n}=22)$ \\
\hline Age & $20.05 \pm 1.25$ & $20.68 \pm 1.12$ \\
\hline
\end{tabular}

Table 2 reveals that, in the control group, there is no statistically significant difference in the outcome between pre-test and post-test, except for SBP, which was slightly lower than in the pre-test $(p=0.03)$.

Table 2: Control group $(n=22)$

\begin{tabular}{llll}
\hline Variable & \multicolumn{2}{l}{ Mean \pm SD } & p-value \\
\cline { 2 - 3 } & Pre-test & Post-test & \\
\hline SBP & $121.68 \pm 11.08$ & $115.41 \pm 13.16$ & $0.03^{*}$ \\
DBP & $76.32 \pm 6.96$ & $74.64 \pm 10.72$ & 0.54 \\
TC & $154.45 \pm 39.46$ & $158.86 \pm 27.73$ & 0.40 \\
\hline${ }^{*} \mathrm{p}<$ 0.05. TC: Total cholesterol, SBP: Systolic blood pressure, DBP: Diastolic blood pressure. &
\end{tabular}

Table 3 also reveals that the mean SBP and DBP are substantially different from the pretest ( $p=0.01$ and 0.03 ) in the intervention group. In the intervention group's post-test, the mean SBP and DBP are substantially different from the pre-test $(p=0.01$ and 0.03 ). However, there is no statistically significant difference in TC outcome.

Table 3: Intervention group $(n=22)$

\begin{tabular}{llll}
\hline Variable & \multicolumn{2}{l}{ Mean \pm SD } & p-value \\
\cline { 2 - 3 } & Pre-test & Post-test & \\
\hline SBP & $120.77 \pm 11.44$ & $113.64 \pm 8.72$ & $0.01^{*}$ \\
DBP & $74.91 \pm 7.36$ & $70.32 \pm 6.39$ & $0.03^{*}$ \\
TC & $147.91 \pm 31.73$ & $142.50 \pm 29.71$ & 0.07 \\
\hline${ }^{*} p<0.05$. TC: Total cholesterol, SBP: Systolic blood pressure, DBP: Diastolic blood pressure. &
\end{tabular}

Table 4 displays, based on the Mann-Whitney U-test, that there is no statistically significant difference in the outcome between the control and intervention groups, except for TC, which was slightly lower than in the pre-test $(p=0.02)$.

Table 4: Control-intervention group

\begin{tabular}{ll}
\hline Variable & $p$-value \\
\hline SBP & 1.00 \\
DBP & 0.26 \\
TC & $0.02^{*}$ \\
\hline${ }^{*} p<0.05$. TC: Total cholesterol, SBP: Systolic blood pressure, DBP: Diastolic blood pressure.
\end{tabular}

\section{Discussion}

The mean age of the participants is 20 years old that includes a young adult category (18-24 years old) based on the World Health Organization [15]. Male aged 20-55 years old has more risk of hypertension and atherosclerosis than females [16]. Some influencing factors are lousy lifestyle, psychological problems, and had no estrogen hormone [17]. Estrogen hormone protects the premenopausal female from atherosclerosis by increasing high-density lipoprotein (HDL) and lowering low-density lipoprotein (LDL) [18].

The current research was conducted after the wet cupping therapy treatment to determine healthy young male adults' health changes. The outcome measures in this study were clinically crucial in preventing high BPs and high cholesterol. Moreover, it is also significant for patients with hypertension and hypercholesterolemia.

The recent research with a large sample size conducted by Aleyeidi et al. measured the effect of wet cupping on SBP and DBP in hypertension patients [9]. A substantial difference compared to baseline was stated by the authors. A more recent study by Allafi and Al-Haifi showed that wet cupping therapy in healthy female adults is useful for reducing SBP and DBP [13]. Both of the studies are similar to that in the present research. However, some studies have different results. According to one research by Aleyeidi et al., there was no significant difference observed between the wet cupping and control groups in SBP or DBP [6]. Another study by Zarei et al. showed that while SBP changed significantly before and after wet cupping, there was no significant DBP [19]. One issue discussed is due to the small sample size.

Wet cupping increases blood supply, reduces stasis, and has beneficial effects due to the reduced blood volume of temporarily reducing BP [20]. Blood removal (which can reach $50 \mathrm{~mL}$ ) through the wet cupping technique decreases its volume in the arteries and directly impacts BP [9]. Capillary dilation frequently happens far from the wet cutting point; it allows the blood artery to restore microcirculation, often displaying a relaxing effect in the clumsy muscle vasodilatation, which lowers BP [21].

The previous study by Zarei et al. showed that the effect of cupping therapy in TC has a significant difference compared to before and after therapy [22]. $A$ recent study by Allafi and Al-Haifi showed that wet cupping therapy effectively reduces TC in 20 healthy female adults [13]. Both of the studies are not in line with the present research. The present study, similar to Refaat et al., showed that wet cupping has no significant effect on lower TC levels but substantially increased HDL and lower LDL levels [21].

This study's principal factor is the decline in total blood cholesterol, resulting in improved metabolic control among participants. The present study has no significant effect on TC, but there is a decrease in TC after an intervention (-5.41). The lower TC levels after wet cupping therapy are caused by the hematological system mechanism, which has a significant effect on the control of coagulation pathways by enhancing 
blood flow and organ oxygenation [23]. Wet cupping is a minor surgical excretory technique with a medical and scientific basis in the purification of the blood and interstitial areas of causative pathogens cholesterol as the processing of metabolic waste. It has properties to inhibit hyperlipidemic development [24], [25]. It can also be an essential technique for enhancing lipoprotein metabolism to protect against atherosclerosis [11].

\section{Conclusion}

This study's results indicate that wet cupping can be useful in decreasing BP and TC. Although the sample size was limited, we could better understand the wet cupping process through this research. Furthermore, this study's lack of blindness, as in all previous wet cupping studies, remains a concern. There is also a need for more studies to study the effectiveness of wet cupping in hypertension and hypercholesterolemia with a greater sample size and longer follow-up time.

\section{Acknowledgment}

The author would like to thank the Nursing Students of Universitas Muhammadiyah Yogyakarta for their participation in this study and Universitas Muhammadiyah Yogyakarta for this project's financial support.

\section{References}

1. Syahruramdhani S, Agustiningsih D, Sofro ZM. The influence of dry cupping toward heart rate variability (HRV) in male obesity adolescence. Mutiara Medika J Kedokt Kesehatan. 2016;16(2):71-5.

2. Lee R, Nieman D. Nutritional Assessment. New York: McGrawHill Education; 2012.

3. Cimminiello C, Zambon A, Polo HF. Hypercholesterolemia and cardiovascular risk: Advantages and limitations of current treatment options. G Ital Cardiol (Rome). 2016;17(4 Suppl 1):6S-13.

4. Kaplan NM. Kaplan's Clinical Hypertension. Philadelphia, PA: Lippincott Williams and Wilkins; 2010.

5. Stapleton PA, Goodwill AG, James ME, Brock RW, Frisbee JC. Hypercholesterolemia and microvascular dysfunction: Interventional strategies. J Inflamm (Lond). 2010;7(1):54 https://doi.org/10.1186/1476-9255-7-54

PMid:21087503

6. Aleyeidi N, Aseri K, Kawthar A. The efficacy of wet cupping on blood pressure among hypertension patients in Jeddah, Saudi Arabia: A randomized controlled trial pilot study. Altern Integr
Med. 2015;4:183. https://doi.org/10.4172/2327-5162.1000183

7. MahmoodL. Nonpharmacologicalcholesterol-loweringapproach: Managing cholesterol naturally. CHRISMED J Health Res. 2015;2(3):193-8. https://doi.org/10.4103/2348-3334.158669

8. Chirali IZ. Traditional Chinese Medicine Cupping Therapy, Philadelphia, PA: Churchill Livinstone, Elsevier; 2007.

9. Aleyeidi NA, Aseri KS, Matbouli SM, Sulaiamani AA, Kobeisy SA Effects of wet-cupping on blood pressure in hypertensive patients: A randomized controlled trial. J Integr Med. 2015;13(6):391-9. https://doi.org/10.1016/s2095-4964(15)60197-2 PMid:26559364

10. Zarei M, Hejazi S, Javadi SA, Farahani H. The efficacy of wet cupping in the treatment of hypertension. ARYA Atheroscler. 2012;8:S145-8

11. Al-Tabakha MM, Sameer FT, Saeed MH, Batran RM, Abouhegazy NT, Farajallah AA. Evaluation of bloodletting cupping therapy in the management of hypertension. J Pharm Bioallied Sci. 2018;10(1):1. https://doi.org/10.4103/jpbs.JPBS_242_17 PMid:29657501

12. Abd El-Ghaffaar HA, Mandour JK, Atia FA. Response of cholesterol to cupping therapy in post-menopausal women with hypercholesterolemia. EurAsian J BioSci. 2020;14(1):123-7.

13. Allafi AR, Al-Haifi AR. The effect of Hijamah on different health parameters. Prog Nutr. 2020;22(2):411-4.

14. Arslan M, Yeşilçam N, Aydin D, Yüksel R, Dane S. Wet cupping therapy restores sympathovagal imbalances in cardiac rhythm. J Altern Complement Med. 2014;20(4):318-21. https://doi. org/10.1089/acm.2013.0291 PMid:24520978

15. World Health Organization. Adolescent Health in the SouthEast Asia Region; 2020. Available from: https://www.who.int/ southeastasia/health-topics/adolescent-health. [Last accessed on 2019 Dec 12]

16. Kusumawaty J, Hidayat N, Ginanjar E. Factors Related Events Sex with Hypertension in Elderly Work Area Health District Lakbok Ciamis. Mutiara Medika J Kedokt Kesehatan. 2016;16(2):46-51. https://doi.org/10.18196/mmjkk.v16i2.4450

17. Rahmayani ST. Risk factors of primary hypertension incidence on aged 20-55 years old at internist polyclinic, RSUD 45 Kuningan. Syntax Idea. 2019;1(4):100-11. https://doi.org/10.22435/bpk. v48i1.2664

18. Waani OT, Tiho M, Kaligis SH. Blood total cholesterol profile on office employee. eBiomedik. 2016;4(2):2-6. https://doi. org/10.35790/ebm.4.2.2016.14606

19. Zarei M, Hejazi S, Javadi A. GW27-e0802 The efficacy of wet cupping in treatment of hypertension. J Am Coll Cardiol. 2016;68(16S):C140-C. https://doi.org/10.1016/j. jacc.2016.07.529

20. Lowe DT. Cupping therapy: An analysis of the effects of suction on skin and the possible influence on human health. Complement Ther Clin Pract. 2017;29:162-8. https://doi. org/10.1016/j.ctcp.2017.09.008 PMid:29122256

21. Refaat B, El-Shemi AG, Ebid AA, Ashshi A, BaSalamah MA Islamic wet cupping and risk factors of cardiovascular diseases: Effects on blood pressure, metabolic profile and serum electrolytes in healthy young adult men. Altern Integ Med. 2014;3(1):151. https://doi.org/10.4172/2327-5162.1000151

22. Sutriyono S, Robbina MR, Ndii MZ. The effects of wet cupping therapy in blood pressure, glucose, uric acid and total cholesterol levels. Biol Med Nat Prod Chem. 2019;8(2):33-6. https://doi. org/10.14421/biomedich.2019.82.33-36

23. Ahmadi A, Schwebel DC, Rezaei M. The efficacy of wetcupping in the treatment of tension and migraine headache. Am J Chin Med. 2008;36(01):37-44. https://doi.org/10.1142/ 


\section{S0192415X08005564}

PMid:18306448

24. Lu S, Du S, Fish A, Tang C, Lou Q, Zhang X. Wet cupping for hypertension: A systematic review and meta-analysis. Clin Exp Hypertens. 2019;41(5):474-80. https://doi.org/10.1080/1064196 3.2018 .1510939
PMid:30183389

25. Umar NK, Tursunbadalov S, Surgun S, Welcome MO, Dane S The effects of wet cupping therapy on the blood levels of some heavy metals: A pilot study. J Acupunct Meridian Stud. 2018;11(6):375-9. https://doi.org/10.1016/j.jams.2018.06.005 PMid:29958995 